Christina E. Adamsen • Mette L. Hansen •

Jens K. S. Møller • Leif H. Skibsted

\title{
Studies on the antioxidative activity of red pigments in Italian-type dry-cured ham
}

Received: 3 February 2003 / Revised: 11 April 2003 / Published online: 17 June 2003

(C) Springer-Verlag 2003

\begin{abstract}
Aqueous phosphate buffer extracts and acetone/water extracts of pigments from Parma ham were assessed as antioxidants by (1) electron spin resonance spectroscopy using a spin probing technique to evaluate their efficiencies as scavengers of free radicals, and (2) by electrochemical measurement of oxygen depletion rate in an aqueous methyl linoleate emulsion to evaluate their efficiencies as chain-breaking antioxidant, and using both methods, compared with the effect of apomyoglobin and nitrosylmyoglobin. Aqueous phosphate extracts and acetone/water extracts of Parma ham pigment both scavenged a semi-stable nitroxide radical (Fremy's salt), and both extracts reduced the rate of oxygen consumption for lipid peroxidation (initiated by metmyoglobin) very efficiently. For apomyoglobin no antioxidative capacity was observed, and the heme moiety of the pigment(s) of Parma ham were concluded to have antioxidative properties. The more lipophilic pigment, as extracted by acetone/water, had the most significant effect, and its ability to inhibit lipid oxidation was further tested in a model food system based on cooked pork. The lipid oxidation was increasingly inhibited by increasing additions from $0.12 \mathrm{ppm}$ to $0.24 \mathrm{ppm}$ Parma ham pigment, and the pigment protected $\alpha$-tocopherol against degradation in a concentration dependent manner.
\end{abstract}

Keywords Dry-cured Parma ham · Pigment extracts . Antioxidative activity - Electron spin resonance spin probing - Oxygen consumption

C. E. Adamsen · M. L. Hansen · J. K. S. Møller .

L. H. Skibsted (

Food Chemistry, Department of Dairy and Food Science,

The Royal Veterinary and Agricultural University, Rolighedsvej 30, 1958 Frederiksberg C, Denmark

e-mail: address: 1s@kvl.dk

Tel.: +45-32-283221

Fax: +45-35-283344

\section{Introduction}

Parma ham is a traditional dry-cured Italian meat product. The ham is made only in the Parma region, from whole raw pork legs and sodium chloride obtained from the Mediterranean Sea. The dry-cured ham is characterised by a unique flavour and texture and it attains a bright red colour during the prolonged salting and maturing process. The red pigment of brine-cured meat and other dry-cured meat is usually produced through the addition of nitrite or nitrate as curing ingredients, which either by endogenous or added reducing compounds reacts with myoglobin to yield nitrosylmyoglobin, MbFe(II)NO. In contrast, Parma ham obtains a stable red colour without nitrite/nitrate treatment, as only sodium chloride is added during the production of Parma ham [1, 2]. During processing two or more fractions of red pigments are present in Parma ham, and in the final dry-cured ham a lipophilic pigment is predominant [3].

Parma ham is known for its oxidative stability during storage even at room temperature, and for its colour stability. In brine-cured meats, $\mathrm{MbFe}(\mathrm{II}) \mathrm{NO}$ has been show to be an antioxidant $[4,5,6]$. The objective of the present study was to explore whether the pigments being formed during the traditional dry-curing process also function as antioxidants. Two different methods were used simultaneously in order to evaluate the effect of Parma ham pigment extracted with a phosphate buffer or an acetone/water solution on oxidative processes. The first method was based on the electrochemical detection of oxygen depletion with a Clark electrode in a peroxidating oil/water emulsion of linoleic acid as an unsaturated lipid model. The second method was based on measurement of radical scavenging using electron spin resonance (ESR) spectroscopy. By this combination, both the ability to either promote or inhibit the propagation phase in lipid oxidation together with radical scavenging abilities to prevent initiation of oxidation can be assessed. For acetone/water extracts of Parma ham pigment, the ability to inhibit lipid oxidation was further tested for different levels in a model food system based on cooked 
pork patties. The cooked pork patties were based on meat from longissimus dorsi (pork), which is a well-characterised muscle. The composition of the cooked pork patties were further analysed by measurement of fat content.

\section{Materials and methods}

Chemicals. Disodium hydrogenphosphate dihydrate, sodium dihydrogenphosphate monohydrate, sulphuric acid (95-97\%), hydrochloric acid (37\%), sodium ascorbate, sodium nitrite, calcium chloride dehydrate, potassium chloride, ammonium thiocyanate, potassium hydroxide and reagents for thiobarbituric acid reactive substances (TBARS) analysis were all of analytical grade and were obtained from Merck (Darmstadt, Germany). Acetone, chloroform, methanol, $n$-hexane and methylethylketone were obtained from Lab-Scan (Dublin, Ireland). 1-Butanol and ammonium ferrous sulphate were obtained from Fluka (Buchs, Switzerland). The semistable nitroxide radical potassium nitrosodisulphonate (Fremy's salt), linoleic acid, Tween 20 and metmyoglobin [MbFe(III), horse heart, Type III] were obtained from Sigma (St. Louis, Mo., USA). $\mathrm{MbFe}$ (III) was dissolved in $5 \mathrm{mM}$ phosphate buffer of $\mathrm{pH} 6.20(\mathrm{pH}$ adjusted to 6.20 with $1.0 \mathrm{M} \mathrm{NaOH}$ ) and filtered through a MiniStar filter with $\Phi=0.45 \mu \mathrm{m}$ (Sartorius, Goettingen, Germany). The $\mathrm{MbFe}$ (III) solution was purified on a PD 10 column (Pharmacia, Uppsala, Sweden) with $5 \mathrm{mM}$ phosphate buffer $(\mathrm{pH}=6.2)$ as eluent, and absorbance at $525 \mathrm{~nm}$ was adjusted to 0.77 , corresponding to a $\mathrm{MbFe}(\mathrm{III})$ concentration of $0.10 \mathrm{mM},\left(\varepsilon=7,700 \mathrm{M}^{-1} \mathrm{~cm}^{-1}\right)$ using a Hewlett-Packard 8452A UV-VIS diode array spectrophotometer (Hewlett-Packard, Palo Alto, Calif., USA). All other chemicals were of analytical grade and used without further purification. Water was purified through a Millipore Q-Plus unit (Millipore, Bedford, Mass., USA).

Meat samples. Fully matured Parma ham (total processing time of 18 months) was obtained from a local producer through Stazione Sperimentale per l'Industria delle Conserve Alimentari (Parma, Italy).

Extraction of Parma ham pigment with phosphate buffer. Lean meat (10 g) was trimmed for any visible fat, chopped very fine and the Parma ham pigment was extracted as describe by Møller et al. [3]. The concentration of Parma pigment in aqueous extract was adjusted to $0.010 \mathrm{mM}$ by measuring the absorbance at $424 \mathrm{~nm}$ $\left(\varepsilon_{424}=152,100 \mathrm{M}^{-1} \mathrm{~cm}^{-1}\right)$ [3]. The extract was used for measurements within $4 \mathrm{~h}$, during which it was kept dark and on ice.

Extraction of Parma ham pigment with acetone/water. The Parma ham pigment was extracted with acetone/water according to the method described be Møller et al. [3]. The concentration of the acetone/water extract was adjusted to $0.010 \mathrm{mM}$ by measuring the absorbance at $416 \mathrm{~nm}\left(\varepsilon_{416}=199,200 \mathrm{M}^{-1} \mathrm{~cm}^{-1}\right)$ [3]. The extract was used for measurements within $4 \mathrm{~h}$, during which it was kept dark and on ice.

Nitrosylmyoglobin. Nitrosylmyoglobin was synthesised from purified $\mathrm{MbFe}$ (III), sodium nitrite and ascorbic acid in an array of Zwickel flasks by the method described by Andersen and Skibsted [7]. The metmyoglobin was diluted with $5 \mathrm{mM}$ phosphate buffer ( $\mathrm{pH}=7.00, \mathrm{pH}$ adjusted with $1.0 \mathrm{M} \mathrm{NaOH}$ ) to $0.2 \mathrm{mM}$, as measured at $525 \mathrm{~nm}\left(\varepsilon_{525}=7,700 \mathrm{M}^{-1} \mathrm{~cm}^{-1}\right)$. The initial concentration of $\mathrm{MbFe}(\mathrm{II}) \mathrm{NO}$ was $0.050 \mathrm{mM}$, determined by absorbance measurement at $525 \mathrm{~nm}\left(\varepsilon_{525}=7,700 \mathrm{M}^{-1} \mathrm{~cm}^{-1}\right)$.

Cleavage of the heme-protein by acid methylethylketone. Apomyoglobin (apoMb), the protein fraction of $\mathrm{MbFe}(\mathrm{III})$, where the heme moiety was detached and separated using methylethylketone, was prepared as described by Teale [8]. The absorbance spectra (200$700 \mathrm{~nm}$ ), measured before and after the reaction with methylethylketone, followed by dialyses was used as a control of the cleavage of the heme-protein. The aqueous protein fraction was, after preparation, diluted to a concentration of $0.010 \mathrm{mM}$. The protein faction was used for measurements within $4 \mathrm{~h}$, during which it was kept dark and on ice.

Preparation of linoleic acid emulsions. Linoleic acid emulsions were prepared in a $10 \mathrm{ml}$ volumetric flask by mixing Tween 20 and linoleic acid $(0.21 \mathrm{mmol})$ with a $5.0 \mathrm{mM}$ phosphate buffer $(\mathrm{pH}=6.0)$ as described by Mikkelsen et al. [9]. The $\mathrm{pH}$ was adjusted to 9.00 with $0.1 \mathrm{M} \mathrm{NaOH}$ to provide the highest possible stability of the emulsion.

Parma pigment effect on peroxidation of linoleic acid emulsions. The effects of the investigated pigments (Parma ham pigment extracted with aqueous buffer, Parma ham pigment extracted with acetone/water solution, $\mathrm{MbFe}(\mathrm{II}) \mathrm{NO}$ and apoMb) were determined by oxygen consumption rate measurements in linoleic acid emulsions. The oxygen consumption rate was measured using a Clark electrode (Radiometer, Copenhagen, Denmark) in connection with a multichannel analyzer and a data collecting system as described by Mikkelsen et al. [9]. The electrode was calibrated by a two-point calibration with anoxic and air-saturated $5 \mathrm{mM}$ phosphate buffers $(\mathrm{pH}=6.0)$ thermostatted at $25^{\circ} \mathrm{C}$. The relative oxygen concentration in the system was recorded every $5 \mathrm{~s}$ for $30 \mathrm{~min}$.

The assay was based on a $0.42 \mathrm{mM}$ linoleic acid emulsion with $0.0020 \mathrm{mM}$ metmyoglobin, air-saturated $5.0 \mathrm{mM}$ phosphate buffer incubated at $25{ }^{\circ} \mathrm{C}$ with Parma ham extract (phosphate extract or acetone/water extract), $\mathrm{MbFe}(\mathrm{II}) \mathrm{NO}$ or apoMb solution added. The following concentrations of Parma ham extracts were investigated: $0.0,0.1,0.2,0.5,1.0$ and $2.0 \mu \mathrm{M}$. The effect on peroxidation of $\mathrm{MbFe}(\mathrm{II}) \mathrm{NO}$ and apoMb was tested at a concentration of $2.0 \mu \mathrm{M}$ both in acetone/water solution and in phosphate buffer. For acetone/water-extracts the total acetone/water concentration was kept at a constant level $(25 \% \mathrm{w} / \mathrm{w})$ at all pigment concentrations. Immediately after mixing, the samples were injected into a $70 \mu \mathrm{l}$ thermostatted $\left(25{ }^{\circ} \mathrm{C}\right)$ measuring cell (Chemiware, Viby $\mathrm{J}$, Denmark) with no headspace.

The effect on oxidative processes was determined using the oxygen consumption rate $v\left(\mathrm{O}_{2}\right)$, expressed in micromoles per litre per second, and was calculated from:

$v\left(\mathrm{O}_{2}\right)=\frac{- \text { slope } \times\left[\mathrm{O}_{2}\right]_{\text {initial }} \times 10^{6}}{100}$

The slope $\left(\mathrm{O}_{2}\right.$ percent per second $)$ was calculated from a plot of oxygen percentage versus time. The linear region of the curve (typically beginning $90 \%$ to $70 \% \mathrm{O}_{2}$ ) was used to determine the slope using linear regression analysis. The initial oxygen concentration, $\left[\mathrm{O}_{2}\right]_{\text {initial }}=2.6 \times 10^{-4} \mathrm{M}$ at $25{ }^{\circ} \mathrm{C}$, was obtained from Ostwald's coefficient of oxygen in pure water. The influence of each of the extracted pigments, MbFe(II)NO and apoMb on the initial rate of oxygen consumption was expressed as an antioxidative index relative to the rate in the absence of extracted pigments, $\mathrm{MbFe}(\mathrm{II}) \mathrm{NO}$ or apoMb:

$\mathrm{I}_{\text {oxygen }}=\left(1-\frac{v\left(\mathrm{O}_{2}\right) \text { with pigment present }}{v\left(\mathrm{O}_{2}\right) \text { without pigment present }}\right) \times 100 \%$

The oxygen consumption assay is only a relative method for comparison among various compounds or extracts $[10,11]$. The index number has been reversed compared to previous studier [10, 11], and a higher value now indicates a more pronounced antioxidative effect.

ESR spectroscopy. The ESR experiments were performed with a standard solution containing $200 \mu \mathrm{l}$ of $1.0 \mathrm{mM}$ aqueous solution of radical anion of Fremy's salt and $3.0 \mathrm{ml}$ of $12 \%$ ethanol. After $3 \mathrm{~min}$, the sample were transferred to an ESR quartz tube (Wilmad, Buena, N.J., USA), and after 4 min $30 \mathrm{~s}$, ESR spectra were recorded on a JEOL JES-FR30 (JEOL, Tokyo, Japan) ESR spectrometer operating in X-band mode. The radical scavenging ability of the extracts (Parma ham extracted with phosphate buffer and Parma ham extracted with acetone-water solution) was tested at concentrations 
of $0.0,0.1,0.5,1.0,2.0$ and $3.33 \mu \mathrm{M}$ Parma ham extract by mixing $200 \mu \mathrm{l}$ of $1.0 \mathrm{mM}$ aqueous solution of Fremy's radicals and $12 \%$ ethanol to a total volume of $3.2 \mathrm{ml}$. The radical scavenging ability of $\mathrm{MbFe}$ (II)NO solution was tested at concentrations of approximately $0.0,0.005,0.01,0.025,0.05,0.1,0.2$ and $0,5 \mu \mathrm{M}$ by mixing $200 \mu \mathrm{l}$ of $1.0 \mathrm{mM}$ aqueous solution of Fremy's radicals and $12 \%$ ethanol to a total volume of $3.2 \mathrm{ml}$. The radical scavenging ability of apoMb was tested at concentrations of 0.0 and $3.33 \mu \mathrm{M}$ extract by mixing $200 \mu \mathrm{l}$ of $1.0 \mathrm{mM}$ aqueous solution of Fremy's radicals and $12 \%$ ethanol to a total volume at $3.2 \mathrm{ml}$. All the spectra were obtained at $25{ }^{\circ} \mathrm{C}$. The following parameters were used in all ESR experiments: microwave power, $4 \mathrm{~mW}$; sweep width, $5 \mathrm{mT}$; sweep time, $0.5 \mathrm{~min}$; modulation width, $0.25 \mathrm{mT}$; and time constant, $0.1 \mathrm{~s}$.

The relative signal intensity was calculated using a manganese internal standard by measuring the peak-height of the second line in the spectrum. The paramagnetic anion of Fremy's salt can be measured by ESR spectroscopy, while its reduction product is ESRsilent. Solutions with no antioxidative activity cause the ESR signal to remain at the same level as the standard.

The radical scavenging ability of Parma ham extracts, solutions of $\mathrm{MbFe}(\mathrm{II}) \mathrm{NO}$ or apoMb solution was calculated as the degree of inhibition $\left(\mathrm{I}_{\mathrm{ESR}}\right)$ :

$\mathrm{I}_{\mathrm{ESR}}=\left(1-\frac{\text { Peak height with pigment present }}{\text { Peak height without pigment present }}\right) \times 100 \%$

Cooked pork patties with Parma ham pigment. Pork meat (longissimus dorsi), pork fat, flour, egg and salt were obtained from a local supermarket. Meat patties are made by mixing $65 \%$ pork, $15 \%$ lard, $8.0 \%$ egg, $4.0 \%$ flour, $0.1 \%$ salt and $8.0 \%$ acetone/ water extract of Parma ham pigment, extracted as previously described. The acetone/water extract of Parma ham pigment was adjusted to $0.24 \mathrm{ppm}, 0.12 \mathrm{ppm}$ and $0.0 \mathrm{ppm}$ in the pork patties (each $15 \mathrm{~g}$ ). The pork patties were placed in $22.5 \times 15.5 \mathrm{~cm}$ pouches of a laminated packaging material of $30 \mu \mathrm{m}$ polyamide (PA)/ $100 \mu \mathrm{m}$ polyethylene (PE) (SFK Meat system, Denmark) with an oxygen transmission rate of $21 \mathrm{~cm}^{3} \mathrm{~m}^{-2} \mathrm{~atm}^{-1} 24 \mathrm{~h}^{-1}$ (at $23{ }^{\circ} \mathrm{C}$ and $5 / 95 \% \mathrm{RH})$, a carbon dioxide transmission rate of $97 \mathrm{~cm}^{3} \mathrm{~m}^{-2} \mathrm{~atm}^{-1}$ $24 \mathrm{~h}^{-1}$ (at $23{ }^{\circ} \mathrm{C}$ and $5 / 95 \% \mathrm{RH}$ ), and a water-vapour transmission rate of $0.8 \mathrm{~g} \mathrm{~cm}^{-2}$ (at $23{ }^{\circ} \mathrm{C}$ and $50 \% \mathrm{RH}$ ) and were vacuum packed (Electronic VacMit, Duggendorf, Germany) and cooked in boiling water for $2 \mathrm{~min}$ and $15 \mathrm{~s}$. After chilling, the meat patties were repacked in $30 \mu \mathrm{m} \mathrm{PA} / 100 \mu \mathrm{m}$ PE laminated bags with atmospheric air in the headspace. The ratio of headspace to meat was approximately $1: 1$.

The samples were stored in the dark in a refrigerator (Termaks series 6000, Termaks, Solheimsviken, Norway), and temperature was monitored continuously during storage using data loggers (Tinytalk II-Temp Loggers, RS Radio Parts, Copenhagen, Denmark). The mean storage temperature was $4.4^{\circ} \mathrm{C}$.

Total fat content. On day 0 , randomly selected samples $(n=3)$ of meat patties with no addition of Parma ham pigment $(0.0 \mathrm{ppm})$ were analysed for total fat content. The fat from the meat patties were extracted by chloroform and methanol by the method of Folch et al. [12].

Lipid oxidation in the meat patties. On days $0,2,4,7$ and 11, randomly selected samples $(n=2)$ of meat patties with three levels of Parma ham extract added were analysed for primary and secondary lipid oxidation products. The content of primary oxidation products was estimated as peroxide value (POV). The fat from the meat patties were extracted by the method of Folch et al. [12]. POVs were measured by a method modified from the International Dairy Federation [13] and Tian and Dasgupta [14]. Extracted fat $(10 \mathrm{mg})$ was dissolved in $2 \mathrm{ml}$ of 1-butanol/methanol $(50 / 50 \mathrm{w} / \mathrm{w} \%)$, and $2 \mathrm{ml}$ of $7.7 \mathrm{mM}$ ammonium ferrous sulphate and $45 \mathrm{mM}$ sulphuric acid in methanol, and $2 \mathrm{ml}$ of $0.13 \mathrm{M}$ ammonium thiocyanate were added and the absorbance at $510 \mathrm{~nm}$ was measured. The contents of lipid hydroperoxides $(\mathrm{LOOH})$ in the extracted fat were calculated on the basis of an iron standard curve and expressed as millimoles of $\mathrm{LOOH}$ per kilogram of fat.
The content of secondary lipid oxidation products was estimated as TBARS by the extraction method of Sørensen and Jørgensen [15]. TBARS were expressed as micromoles of malonaldehyde per kilogram of meat.

On days 0 and day 11, the vitamin E content (micrograms of $\alpha$ tocopherol per gram of meat) was analyzed by the method of Jensen et al. [16]. Two randomly selected samples of meat patties with three levels of Parma ham extract added were analyzed and the decompositions expressed as $\alpha$-tocopherol were expressed as $\Delta \alpha$ tocopherol per gram of meat (\%).

$$
\begin{aligned}
& \Delta \alpha \text {-tocopherol/g meat }(\%)
\end{aligned}
$$

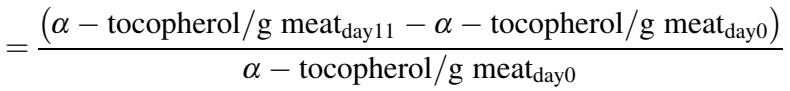

$$
\begin{aligned}
& \times 100 \%
\end{aligned}
$$

\section{Data analysis}

Two types of data were obtained:

1. Oxygen consumption rate $v\left(\mathrm{O}_{2}\right)$ in micromoles per litre per second for Parma ham pigment extracted with acetone/water and with phosphate buffer at concentrations of $0.0,0.1,0.2,0.5,1.0$ and $2.0 \mu \mathrm{M}$. The $\mathrm{MbFe}(\mathrm{II}) \mathrm{NO}$ and apoMb with acetone/water and with phosphate buffer were tested at a concentration of $2.0 \mu \mathrm{M}$.

2. The radical scavenging ability calculated as the degree of inhibition ( $\mathrm{I}_{\mathrm{ESR}}$ ) of Fremy's salt by Parma ham pigment extracted with acetone/water and phosphate buffer, for $\mathrm{MbFe}(\mathrm{II}) \mathrm{NO}$ and apoMb

Measurement of control samples and samples containing Parma ham pigment extract, solutions of $\mathrm{MbFe}$ (II)NO or apoMb solution were in each case performed on the same day. The measurements of the extracts of Parma ham pigments, solutions of $\mathrm{MbFe}(\mathrm{II}) \mathrm{NO}$ and apoMb solution were done in triplicate as minimum. The two sets of data were statistically analyzed using the general linear model procedure in SAS Ver. 8.2 (SAS, Cary, N.C., USA). Analyses of variance were performed to find the significant effects of the type of pigment (Parma ham pigment extracted with acetone/water, Parma ham pigment extracted with phosphate buffer and $\mathrm{MbFe}(\mathrm{II})$ NO) or pigment concentration.

\section{Results and discussion}

Mean values of the inhibition index, $\mathrm{I}_{\text {oxygen }}$, are reported in Table 1 for Parma ham pigments extracted with phosphate buffer, Parma ham pigments extracted with acetone-water solution, $\mathrm{MbFe}(\mathrm{II}) \mathrm{NO}$ and apoMb at different concentrations. Parma pigment extracted both with acetone/water and phosphate buffer were observed to have a clear antioxidative effect in the peroxidating linoleic acid emulsion. The antioxidative activity of the Parma ham pigments was dependent on the concentration tested $(P<0.001)$, and on the extraction methods $(P<0.001)$ and antioxidative activity of both extracts was seen to increase in a concentration dependent manner (Table 1), which is observed as an increase of value for Ioxygen with increasing concentrations of Parma ham pigment.

For Parma ham pigment extracted with acetone/water, a significant antioxidative effect of the pigment at concentrations higher than $0.2 \mu \mathrm{M}$ was observed in the peroxidating lipid emulsion. For Parma ham pigment 
Table 1 Antioxidative activity, measured as $\mathrm{I}_{\text {oxygen }}(\%)$, for Parma ham pigments extracted with phosphate buffer, Parma ham pigments extracted with acetone-water solution, $\mathrm{MbFe}(\mathrm{II}) \mathrm{NO}$ solution and solutions of protein fraction of $\mathrm{MbFe}(\mathrm{III})$ at different concentrations in linoleic acid emulsions with metmyoglobin as a prooxidant. As acetone has an influence on the assay, MbFe(II)NO and apoMb were measured both with acetone-water solution and phosphate buffer. Values are the means of four independent measurements \pm standard deviations. Negative values indicate prooxidative effect. ApoMb Apomyoglobin (protein fraction of $\mathrm{MbFe}(\mathrm{III})$ where the heme moiety was detached and separated using methylethylketone)

Concentration

Type of extract/sample

Parma ham pigment (acetone/water)

Parma ham pigment (phosphate buffer)

$\mathrm{MbFe}(\mathrm{II}) \mathrm{NO}$ (acetone/water)

$\mathrm{MbFe}(\mathrm{II}) \mathrm{NO}$ (phosphate buffer)

ApoMb (acetone/water)

ApoMb (phosphate buffer)

$\begin{array}{crrcc}0.1 \mu \mathrm{M} & 0.2 \mu \mathrm{M} & 0.5 \mu \mathrm{M} & 1 \mu \mathrm{M} & 2 \mu \mathrm{M} \\ 0.2 \pm 12.1 & 54.0 \pm 5.4 & 79.5 \pm 9.8 & 89.1 \pm 2.8 & 85.0 \pm 4.1 \\ 34.9 \pm 4.5 & 45.8 \pm 5.0 & 33.2 \pm 6.1 & 43.0 \pm 3.4 & 72.8 \pm 6.3 \\ & & & 75.4 \pm 2.2 \\ & & & 54.8 \pm 3.2 \\ & & & -5 \pm 10 \\ & & & -5.2 \pm 2.6\end{array}$

extracted with phosphate buffer, the results presented in Table 1 show an antioxidative effect of the pigment at a concentration of $0.1 \mu \mathrm{M}$, but no further increase in the antioxidative effect was found at concentrations between 0.1 and $1.0 \mu \mathrm{M}$. As for $\mathrm{MbFe}(\mathrm{II}) \mathrm{NO}$ in acetone/water, and Parma ham pigment extracted with acetone/water, the oxygen consumption rate at a concentration of $2 \mu \mathrm{M}$ was not significantly different, showing that the more lipophilic Parma pigment has an antioxidative activity comparable to that of $\mathrm{MbFe}(\mathrm{II}) \mathrm{NO}$. For $\mathrm{MbFe}$ (II)NO in phosphate buffer and Parma ham pigment extracted with phosphate buffer, both at a concentration of $2 \mu \mathrm{M}$, the opposite effect was found: thus, the more lipophilic Parma pigment had a higher antioxidative effect than the pigment in phosphate buffer. A similar antioxidative effect of $\mathrm{MbFe}$ (II)NO has previously been demonstrated for $\mathrm{MbFe}$ (III)-induced peroxidation as measured by rate of oxygen depletion in a methyl linoleic emulsion [4].

$\mathrm{ApoMb}$, where the heme moiety was detached and separated by methylethylketone, followed by dialyses, exhibited no antioxidative effect in the oxygen depletion assay at a concentration of $2 \mu \mathrm{M}$, both dissolved in acetone/water and in phosphate buffer. The detachment of the heme moiety was controlled by absorption spectroscopy $(200-700 \mathrm{~nm})$. The heme moiety was successfully separated from the protein part of $\mathrm{MbFe}$ (III) as shown in Fig. 1 by the absence of the Soret-band and the minor bands for $\mathrm{MbFe}$ (III) after separation of the heme moiety. At $280 \mathrm{~nm}$, proteins show a strong absorption, primarily due to tryptophan and tyrosine residues in the protein [17], and such a protein band is clearly observed before and after detachment of the heme moiety. Even the small prooxidative effect (Table 1) of the apoMb shows that the prosthetic heme group of $\mathrm{Mb}$ with its redox active iron atom is involved in the antioxidative mechanism of Parma ham pigment.

Based on results obtained by measurements of oxygen consumption rate, it is thus evident that Parma ham pigments had an antioxidative activity. Furthermore, the experimental data show that the antioxidative activity of Parma pigment is comparable to that of $\mathrm{MbFe}(\mathrm{II}) \mathrm{NO}$ based on the oxygen consumption rate.

Figure 2 shows ESR signals for the standard solution of the radical anion and two concentrations of Parma ham

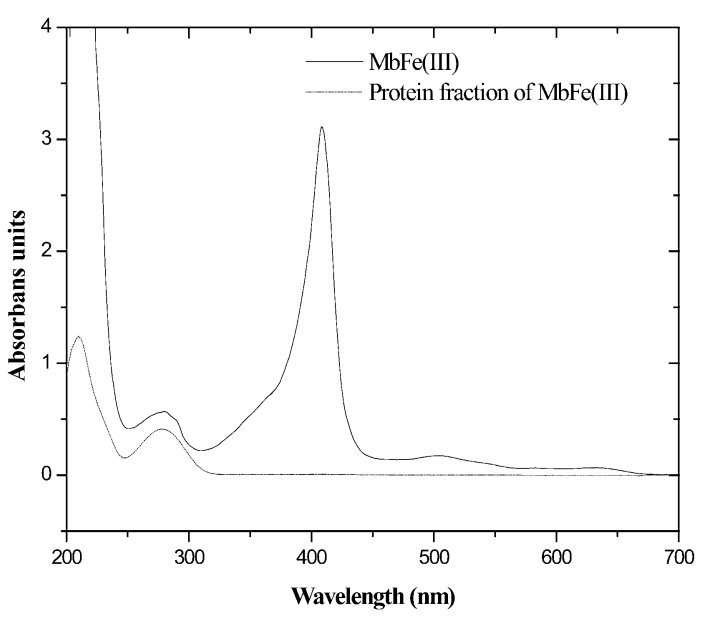

Fig. 1 Absorbance spectra $(200-700 \mathrm{~nm})$ of metmyoglobin $[\mathrm{MbFe}(\mathrm{III})]$ solutions before and after the heme moiety was detached and separated by methylethylketone. The spectra are normalised

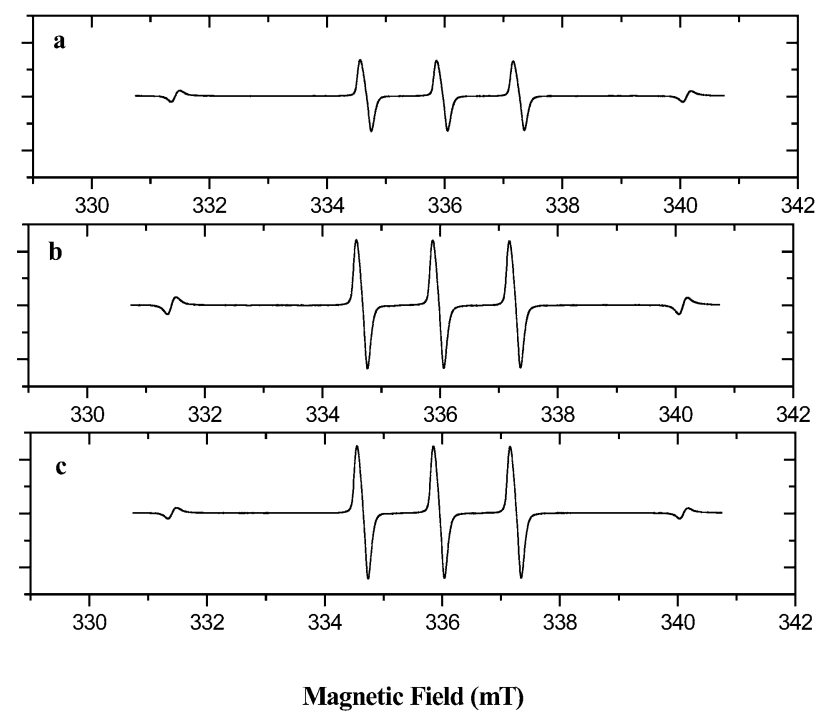

Fig. 2a-c Electron spin resonance spectra of Parma ham pigments extracted with acetone/water solution incubated with aqueous solution of Fremy's salt radicals at $25^{\circ} \mathrm{C}$. The Parma ham pigment concentration was $3.3 \mu \mathrm{M}$ (a), $1.0 \mu \mathrm{M}$ (b) and $0.00 \mu \mathrm{M}$ (control) (c). The initial and terminal peaks are due to manganese internal standard 


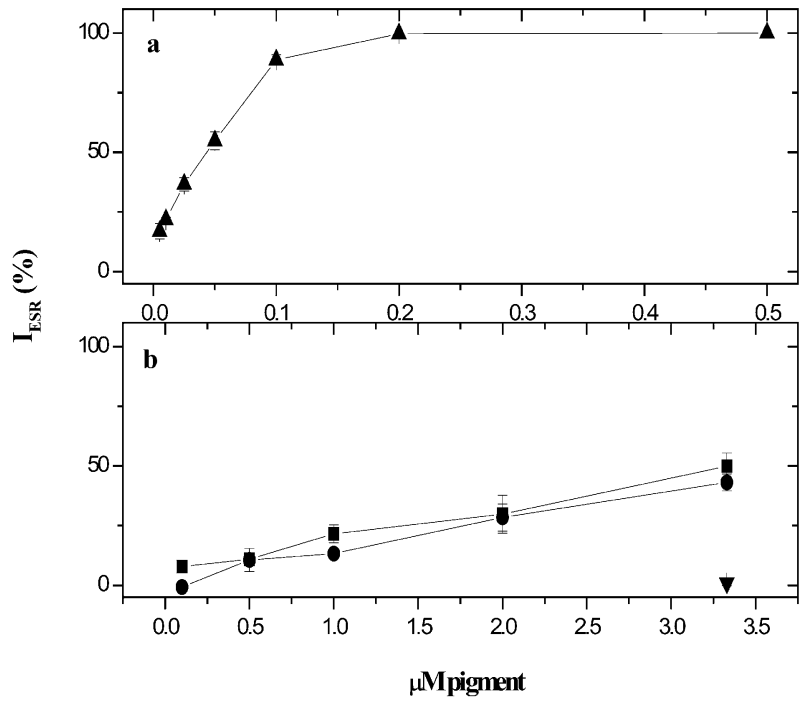

Fig. 3 (a)Degree of inhibition $\left(I_{E S R}\right)$ of Fremy's salt by nitrosylmyoglobin (upright triangle) at the following concentrations: $0.005,0.01,0.025,0.05,0.1,0.2$ and $0.5 \mu \mathrm{M}$ incubated with aqueous solution of radical anion of Fremy's salt at $25^{\circ} \mathrm{C}$. (b) Degree of inhibition ( $\mathrm{I}_{\mathrm{ESR}}$ ) of Fremy's salt by Parma ham pigment extracted with acetone/water (square) and phosphate buffer (circle) at the following concentrations: $0.1,0.5,1.0,2.0$ and $3.3 \mu \mathrm{M}$, and for the $3.3 \mu \mathrm{M}$ protein fraction of $\mathrm{MbFe}(\mathrm{III})$ (inverted triangle)

pigments extracted with acetone/water, i.e. $3.3 \mu \mathrm{M}$ and $1.0 \mu \mathrm{M}$, all measured relative to an internal manganese standard. The intensity of the ESR spectra decreased with increasing Parma ham pigment concentration showing that the Parma pigment is capable of radical quenching.

The radical scavenging abilities of Parma ham extracts and of $\mathrm{MbFe}$ (II)NO solution were calculated as the degree of quenching of the radical anion $\left(\mathrm{I}_{\mathrm{ESR}}\right)$ and both Parma ham extracts and $\mathrm{MbFe}(\mathrm{II}) \mathrm{NO}$ were found to be radical scavengers. $\mathrm{I}_{\mathrm{ESR}}$ increased with increasing concentration of both Parma ham pigments and of MbFe(II)NO (Fig. 3). The results show significant effects $(P<0.001)$ of the tested concentrations for the Parma ham pigment extracted with acetone/water, for Parma ham pigment extracted with phosphate buffer and for $\mathrm{MbFe}(\mathrm{II}) \mathrm{NO}$. There was, however, a significant difference $(P<0.05)$ between $\mathrm{I}_{\mathrm{ESR}}$ for the Parma ham pigment extracted with acetone/water and Parma ham pigment extracted with phosphate buffer, with the more lipophilic pigment extracted with acetone/ water showing the highest quenching activity. The radical scavenging ability of $\mathrm{MbFe}(\mathrm{II}) \mathrm{NO}\left(0.5 \mu \mathrm{M} ; \mathrm{I}_{\mathrm{ESR}}=100 \%\right)$ was higher than for the Parma ham pigment at the same concentration $\left(0.5 \mu \mathrm{M} ; \mathrm{I}_{\mathrm{ESR}}\right.$ acetone/water $=10.9 \%$ and $\mathrm{I}_{\mathrm{ESR}}$ phosphate $=10.6 \%)$. ApoMb, in which the heme moiety was detached and separated by methylethylketone, exhibited no significant effect on the signal intensity of Fremy's salt at a concentration of $3.3 \mu \mathrm{M}$. This indicates that the prosthetic heme group of myoglobin with its redox active iron atom is involved in the radical scavenging capacity of the Parma ham pigments, as also seen for the oxygen consumption assay.
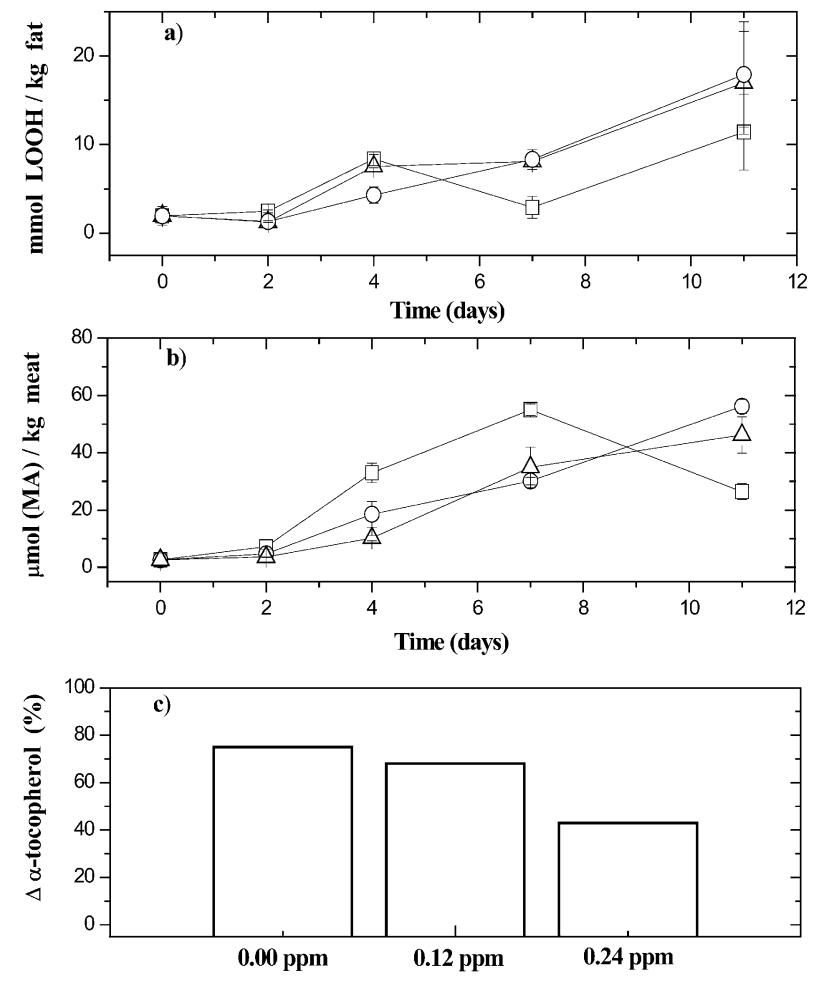

Fig. 4a-c Lipid oxidation (a) measured as peroxide value, (b) measured as TBARS, and (c) as decomposition of $\alpha$-tocopherol from day 0 to day 11 for meat patties containing $0.00 \mathrm{ppm}$ Parma ham pigment (square), $0.12 \mathrm{ppm}$ Parma ham pigment (triangle) and $0.24 \mathrm{ppm}$ Parma ham pigment (circle). The meat patties were cooked and packed in atmosphere air and stored at $4.4{ }^{\circ} \mathrm{C}$ for 12 days. $\mathrm{LOOH}$ Lipid hydroperoxides, $M A$ Malonaldehyde

Based on results obtained by measurements of $\mathrm{I}_{\mathrm{ESR}}$, it is evident that the Parma ham pigments have a radical scavenging ability although it is clearly less efficient than that of $\mathrm{MbFe}(\mathrm{II}) \mathrm{NO}$.

Based on the results obtained by the ESR and the oxygen consumption assay, the antioxidative properties of acetone/water extracted Parma ham pigment were tested in cooked pork patties as a food model system. The total fat content of the cooked pork patties was $13.7 \pm 0.8 \%$. Primary and secondary lipid oxidations products were measured as POVs and TBARS values, respectively, during a 12-day chill storage experiment. The contents of $\alpha$-tocopherol were also measured, at storage days 0 and 11. Development of lipid oxidation in the meat patties during chill storage varied according to their content of Parma ham pigment. As may be seen from Fig. 4, lipid oxidation was most pronounced in the meat patties with no addition of Parma ham pigment, followed by meat patties containing $0.12 \mathrm{ppm}$ and $0.24 \mathrm{ppm}$ Parma ham pigment, respectively. For the meat patties with no addition, POVs and TBARS values rose rapidly, followed by a drop in both POVs and TBARS values at the end of the storage. For meat patties with 0.12 and $0.24 \mathrm{ppm}$ Parma pigment a delayed increase in POVs and the TBARS values was seen. 
The largest decrease in $\alpha$-tocopherol content of the meat patties from day 0 to day 11 was observed for meat patties with no addition followed by meat patties containing $0.12 \mathrm{ppm}$ and $0.24 \mathrm{ppm}$ Parma ham pigment, respectively; thus Parma ham pigment does seem to limit the oxidation in cooked pork meat patties.

Nitrite has multiple functions as a meat additive, including anti-microbial effects, contribution to colour and flavour formation, and protection against oxidative processes. The antioxidative effect of nitrite is not well documented, but the interaction with the iron of heme proteins, or stabilisation of unsaturated lipids within membranes is believed to be important $[4,5,6]$. Studies of oxidative processes in Parma ham are limited, but Chizzolini et al. found that most volatile molecules identified in dry-cured ham are lipid related [18]. Lipid oxidation is, therefore, considered to be a key process in flavour formation. Vestergaard and Parolari showed that the lean part of Parma ham was rather unaffected by oxidation, while the external fat of Parma ham contained some oxidation products, recognised as POVs, TBARS values and cholesterol oxidation products [19]. From this study, it was concluded that good manufacturing practice will generally prevent oxidative damage in the edible part of Parma ham despite the long ageing period. The drycured ham variant, Parma ham, is thus resistant to oxidative rancidity even without the use of nitrate/nitrite in the manufacturing process.

The mechanism of formation and the exact chemical identity of the pigments of Parma ham are still unknown. The pigment of Parma ham differs, however, clearly from $\mathrm{MbFe}(\mathrm{II}) \mathrm{NO}$, which is the pigment of other cured meat products $[3,20]$. Studies dealing with the stability of the Parma ham pigment have shown that an aqueous extract of Parma ham is stable toward oxidation by ferricyanide and is also rather stable toward thermal autoxidation [21]. Moreover, the red pigment of Parma ham, extracted with either $75 \%$ acetone/water solution or with aqueous buffer is stable in darkness for 7 days. The same study clearly showed that the acetone/water extract of the pigment oxidised within 3 days when kept under light at $4{ }^{\circ} \mathrm{C}$ and $20{ }^{\circ} \mathrm{C}$ [21]. Furthermore, no effect of vitamin $\mathrm{E}$ on colour intensity or stability were observed in Parma ham manufactured from pigs supplemented with vitamin $\mathrm{E}$ in comparison to pigs from a normal feeding regime [22].

The stable red pigment of Parma ham could prove useful for meat processing as a food grade red colorant, provided that it could be produced by some biotechnological process. Development of stable red meat colours without application of nitrite or nitrate or addition of other colour-forming agent in meat products is interesting, as it may constitute a way to provide satisfactory colour and colour stability of organically produced meat products.

In conclusion, the oxygen consumption assay and the radical probing assay both identified Parma ham pigments extracted with an acetone/water solution and phosphate buffer as antioxidants. Phosphate buffer extracts and acetone/water extracts of Parma ham pigment both scavenged the semi-stable nitroxide radical and reduced oxygen consumption of a peroxidating lipid model in contrast to the apoMb, and the effect was confirmed in a pork food model. It is notable that the Parma pigment protects $\alpha$-tocopherol against decomposition. The effect of the Parma pigments on lipid oxidation may further be assigned to the propagation phase rather than to the initiation, as the radical scavenging is less evident than the effect on oxygen consumption. Our current work is concentrated on identifying the chemical structure of the Parma pigment(s) and the mechanism behind its antioxidative capacity.

Acknowledgements The present study was founded by the Basis Research Funding Programme of the Danish Bacon and Meat Council. Furthermore, we would like to thank Dr. Giovanni Parolari, Stazione Sperimentale per l'Industria delle Conserve Alimentari, Parma, Italy, for the kind donation of Parma ham samples.

\section{References}

1. Parolari G (1996) Food Sci Technol Int 2:69-78

2. Sakata R (2000) Anim Sci J 71:1-16

3. Møller JKS, Adamsen CE, Skibsted LH (2003) Eur Food Res Technol 216:290-296

4. Møller JKS, Sosniecki L, Skibsted LH (2002) Biochim Biophys Acta 1570:129-134

5. Skibsted LH (1992) Cured meat products and their oxidative stability In: Johnston DE, Knight MK, Ledward DA (eds) The chemistry of muscle-based foods. The Royal Society of Chemistry, Cambridge, pp 266-286

6. Freybler LA, Gray JI, Asghar A, Booren AM, Pearson AM, Buckley DJ (1993) Meat Sci 33:85-96

7. Andersen HJ, Skibsted LH (1992) J Agric Food Chem 40:1741-1750

8. Teale FWJ (1959) Biochim Biophys Acta 35:543

9. Mikkelsen A, Sosniecki L, Skibsted LH (1992) Z Lebensm Unters Forsch 195:228-234

10. Hu M, Skibsted LH (2002) Food Chem 76:327-333

11. Møller JKS, Lindberg-Madsen H, Aaltonen T, Skibsted LH (1999) Food Chem 64:215-219

12. Folch J, Lees M, Stanley GHS (1957) J Biol Chem 226:497509

13. International Dairy Federation (1991) IDF standards 74A:1991 IDF Bruxelles

14. Tian K, Dasgupta PK (1999) Anal Chem 71:2053-2058

15. Sørensen G, Jørgensen SS (1996) Z Lebensm Unters Forsch 202:205-210

16. Jensen C, Guidera J, Skovgaard IM, Staun H, Skibsted LH, Jensen SK, Møller AJ, Buckley J, Bertelsen G (1997) Meat Sci 45:491-500

17. Gabor E (1979) Acta Aliment 8:157-167

18. Chizzolini R, Novelli E, Zanardi E (1998) Meat Sci 49:87-99

19. Vestergaard CS, Parolari G (1999) Meat Sci 52:397-401

20. Sakata R, Niu J, Morita H, Nagata Y (1998) Physicochemical characteristics of red pigment in Parma ham. In: Diestre A, Monfort JM (eds) Congress Proceedings, Meat Consumption and culture, 44th International Congress of Meat Science and Technology, August 30th - September 4th, 1998, Barcelona, Spain. Estrategias Alimentarias, Madrid, Spain, pp 988-989

21. Sakata R, Morita H, Norimastsu T, Niu J (1999) Jpn J Swine Sci 36:124-129

22. Zanardi E, Novelli E, Ghiretti GP, Dorigoni V, Chizzolini R (1999) Food Chem 67:163-171 